\title{
Destination Image and Tourism Satisfaction: The Case of a Mediterranean Destination
}

\author{
Barbara Puh, Ph. D. \\ University of Dubrovnik, Department of Economics and Business Economics, Croatia \\ Email: barbara.puh@unidu.hr
}

Doi:10.5901/mjss.2014.v5n13p0538

\begin{abstract}
In tourism industry the competitiveness among tourism destinations has become increasingly demanding. A large number of existing and new destinations are competing to attract tourists in order to enhance their results as well as to gain better position on international tourism market. Creating and managing destination image is becoming one of the key sources of competitive advantage and one of the important elements in the process of selection of destination. On the other side image is considered as one of the relevant factors in a process of evaluation of services by tourists since it moulds the expectations tourists have before visiting destination. Numerous authors have pointed out that destination image influences tourism satisfaction since destinations with positive image experience more visits and greater satisfaction of tourists. The aim of this paper is to determine the factors that influence destination image and to explore the relationship between destination image and tourism satisfaction. The research was carried out in Dubrovnik, Croatia on a sample of 705 tourists. The SEM results indicate: (1) that natural resources and natural environment, economical factors and social environment as well as tourist leisure and recreation and atmosphere of the place have positive influence on a destination image, (2), that destination image has positive effect on tourism satisfaction.
\end{abstract}

Keywords: destination image, tourism satisfaction, structural equation modelling (SEM)

\section{Introduction}

Tourism sector changes, growing competition among existing and new destinations, as well as changes in tourism expectations and habits, force destinations to find new ways of attracting tourists in order to stay competitive. Researches are showing that image is becoming one of the key factors in destination choice (Schneider and Somnez, 1999; Bigne et al., 2001; Gallarza et al. 2002; Beerli and Martin, 2004; Castro et al., 2007; Chen and Tsai, 2007; Chi and Qu, 2008; Lee, 2009; Wang and Hsu, 2010) and that destination with strong and positive image has higher probability of being chosen by the tourists (Hunt, 1975; Gartner and Shen, 1992; Echtner and Ritchie, 1993; Beerli and Martin, 2004; Lee, 2009). Taking into consideration the intangibility of tourism product, image is becoming the only mean that potential tourist has in comparation and selection of destination (O'Leary and Deegan, 2005.) because what motivates consumer/tourist to act or not to act are perceptions rather than reality (Gallarza et al., 2002, p. 57). Nevertheless destination image, perceived post visit, influences tourism satisfaction depending on the destination capacity to provide experiences that correspond with their needs, and as well as with the image that tourists had before visiting (Chon, 1990; Bigne et al., 2001). So, image plays a fundamental role in the success of tourism destinations since it strongly influences the choice of a destination and tourism satisfaction (Chon, 1990; Bigne et al., 2001; Bigne Alcaniz et al.,2005; Castro et al., 2007; Hernandez -Lobato et al., 2006; Chi and Qu 2008; Prayag, 2009; Xia et al., 2009; Wang and Hsu, 2010; Prayag and Ryan, 2011). Therefore, destination image and especially factors influencing it are becoming extremely important for good positioning of destinations on international tourism market and, if it is/are positive, can increase competitive advantages of a destination.

Although destination image has received considerable academic interest in the past forty years, and scholars agree that it is a complex, multidimensional concept (Gallarza et al. 2002; Prayag, 2009), there is no consensus about its dimensions (Leisen, 2001; Beerli and Martin, 2004; Bigne Alcaniz et al., 2008) leaving space for further researches.

For the purpose of this research, adjusted attributes /dimensions presented in Beerli and Martin (2004) are used to define factors influencing destination image of the city of Dubrovnik, one of the leading destinations on the Adriatic coast. SEM model is used to define relations between factors and destination image as well as between destination image and tourism satisfaction.

\section{Literature Review}

Interest of scholars in number of disciplines regarding the concept of image started with early works of Boulding and 
Martineau in the late 1950es proposing that human behaviour depends upon perceived image rather than objective reality (Baloglu and McCleary,1999a; Wang and Hsu, 2010). Hunt's statement that pictures that potential tourists have of destination are very important in a process of destination selection and can influence it's sustainability became an axiom for scholars in tourism field (Pike, 2007) creating general consensus about importance of image for destination sustainability and effective positioning (Tasci and Gartner, 2007).

Destination image is usually defined as set of beliefs, ideas and impressions that people have about some place or destination (Crompton, 1979). A great number of scholars focus their attention on holistic nature of image, defining destination image as the expression of all knowledge, impressions, prejudices and emotional thoughts that individual or group of people has about particular object or place (Hunt, 1975; Fakeye and Crompton, 1991). Recent studies view destination as a multidimensional construct consisting of rational (cognitive image) and emotional (affective image) interpretations (Baloglu and McCleary, 1999a; Beerli and Martin, 2004). The cognitive image refers to the beliefs or knowledge that a person has of the characteristics or attributes of tourism destinations (Pike and Ryan, 2004). The attributes are the elements of destination that attract tourist to visit a destination (Beerli and Martin, 2004). Affective image refers to the tourist's feelings towards destination (Baloglu and Brinberg, 1997; Baloglu and McCleary 1999b). Although many authors agree that image is formed by two interconnected components -cognitive and affective-(Baloglu and Brinberg, 1997.; Baloglu and McCleary, 1999a.; 1999b.; Beerli and Martin, 2004.; Hernandez Lobato et al., 2006.; Chung - Hsien et al,. 2007.; Hosany et al., 2007.; Okumus and Yasin, 2008.) a lot of conducted studies are neglecting the affective component (Pike, 2002) defining image only on the cognitive component which is considered inappropriate due to the fact that image does not depend only on physical characteristics of destination. The combination of cognitive and affective image gives rise to an overall image that is greater than the sum of the parts (Fakeye and Crompton, 1991; Wang and Hsu, 2010). Overall image can be similar to or different from cognitive or affective perceptions of the destination (Baloglu and McCleary 1999a; Wang and Hsu, 2010). So in order to measure the image of a destination Ahmed (1991) suggests that the evaluation of overall image as well as its two components is necessary to understand the positioning of destination.

Tourism satisfaction is considered to be a central concept in tourism (Chen and Tsai, 2007; Prayag, 2009) since it influences the choice of a destination, the consumption of products and services and the decision to return (Kozak and Rimmington, 2000; Armario, 2008). It is an important indicator of the tourism sector activity giving crucial feedback of how good the services are delivered (Prebežac and Mikulić, 2008). Although there is general agreement about the importance of customer satisfaction at the destination level in improving destination competitive position the definition of the concept remains varied. One of the most cited definitions is given by Oliver who said that satisfaction is defined as pleasurable fulfilment (Giese and Cote, 2000, p.1). That means that the consumer senses that consumption fulfils some need or desire and that this fulfilment is pleasurable. This view on satisfaction reflects its cognitive nature (exercise in comparation of expectations and performance) on one side, and its affective nature (associated feeling) on the other side (Hernandez-Lobato et al., 2008). In the case of tourism destination, tourists value the degree of pleasurable fulfilment of their needs and wishes on a full range of services offered in a destination so satisfaction depends on the experience they have with using those services. Baker and Crompton (2000) defined satisfaction as emotional condition of tourist after the experience of travelling high lightening only affective nature of satisfaction while Chon (1989) concluded that tourism satisfaction is based on the coincidence of the expectations tourist have before visiting destination and the results of experiences achieved in the destination which represents a comparation between previous image tourist had about destination and those he really sees, feels and remembers about destination.

In the terms of satisfaction measurement most authors agree it is important to differentiate overall destination satisfaction and attribute satisfaction on the destination level (Chi and Qu, 2008.; Bigne et al., 2001.; Castro et al., 2007.; Faullant et al., 2008). The reason lies in a fact that overall satisfaction with a destination is much broader term than the sum of attribute satisfaction (Bigne et al., 2001), so tourism satisfaction measurement must be based on the overall satisfaction dimension (Truong and Foster, 2006).

Researching the relations between destination image and tourism satisfaction became popular in the last fifteen years. The increased life standard resulted in increased tourist demand giving tourist the opportunity to travel to numerous destinations. In such surrounding the perceptions tourist have about particular destination are becoming more and more important. In order to stay competitive destination must be perceived as safe (Troung and King, 2009) products and services must be attractive and better than the ones from competitive destinations. It is becoming very important to understand how tourists perceive destination, its products and services and how these components influence tourism satisfaction. Previous studies show that the image of a destination has positive influence on tourism satisfaction (Chon, 1990.; Bigne et al., 2001.; Bigne Alcaniz et al., 2005.; Castro et al., 2007.; Hernandez -Lobato et al., 2006.; Chi and Qu 2008.; Prayag, 2009.; Xia et al., 2009.; Wang and Hsu, 2010.; Prayag and Ryan, 2011) and that image is a critical factor 
in influencing tourism satisfaction (O'Leary and Deegan, 2005; Cai, Wu and Bai, 2003.; Castro et al., 2007.).

\section{Methodology}

A questionnaire composed of four parts was used in this research: Section 1 enquired about the basic background data of the tourist vacation in a destination, that is questions about number of visits to the destination, the purpose of travelling, duration of the stay and companionship; Section 2 included forty two attributes of the destination in a form of statements defined on a 5 point Likert scale (1- strongly disagree, 5 -strongly agree) in order to define factors influencing destination image; Section 3 involved question to define overall image on a 5 point Likert scale (1- very negative, 5 - very positive) and question to define tourism satisfaction (1- very unsatisfied, 5- very satisfied); Section 4 included demographic information of the respondent: gender, age, country of residence, marital status, education and annual household income.

The questionnaire was carried out in Dubrovnik, Croatia, on a purposive sample of 705 tourists visiting hotels and private accommodation in a period May- September 2010, with a response rate of $68 \%$.

To ensure the reliability of measurement scales Cronbach Alfa coefficient together with Alpha if item deleted and CR (Composite Reliability) were used. Convergent and discriminant validity of measurement scales are tested using exploratory factor analysis (with Varimax raw rotation) and confirmatory factor analysis (RMSEA index, CMIN/DF indicator and AVE).Structural equation model (SEM) was used to test relationship between factors and destination image as well as between destination image and tourism satisfaction. Statistical software SPSS, Smart PLS and AMOS are used for data processing.

\section{Results and Discussion}

The sample profile shows that $53.5 \%$ respondents were females and $2 / 3$ of the participants were between 18 and 49 years old (67.2\%). Most of respondents have college of faculty degree (73.4\%), are married (56.2\%), and $62.2 \%$ have annual household income between 30 and 75 thousand euros. 80.9\% visited Dubrovnik for the first time, for the vacation purposes (87.5\%), with family (60\%) with an average stay of 6-7 days (34.6)\%.

Table 1: The results of Cronbach Alfa and Composite reliability for measurement scales

$\begin{array}{lcc}\quad \text { Measurement scale } & \text { Cronbach alfa coefficient } & \text { Composite reliability (CR) } \\ \text { Elements of natural resources and natural environment } & 0.601 & 0.636 \\ \text { Elements of general and touristic infrastructure } & 0.772 & 0.747 \\ \text { Elements of tourist leisure and recreation } & 0.697 & 0.775 \\ \text { Elements of culture, history and art } & 0.786 & 0.744 \\ \text { Economic factors and social environment } & 0.662 & 0.789 \\ \text { Atmosphere of the place } & 0.702 & 0.731\end{array}$

Source: Results of the research

Results of Cronbach alfa coefficient as well as composite reliability (CR) show that all measurement scales have satisfactory level of reliability as follows: elements of natural resources and natural environment (Cronbach alfa $=0.601$, $\mathrm{CR}=0.636$ ), elements of general and touristic infrastructure (Cronbach alfa $=0.772, \mathrm{CR}=0.747$ ), elements of tourist leisure and recreation (Cronbach alfa $=0.697, C R=0.775$ ), elements of culture, history and art (Cronbach alfa $=0.786$, $\mathrm{CR}=0.744$ ), economic factors and social environment (Cronbach alfa $=0.662, \mathrm{CR}=0.789$ ), atmosphere of the place (Cronbach alfa $=0.702, C R=0.731$ ). Alpha if item deleted is measured for each of forty two statements and those that lower reliability of each measurement scale are excluded from further research (three statements). 
Table 2: Factor structure (with Varimax rotation)

\section{Factors}

Dubrovnik is a town with pleasant climate $\quad .607$

Dubrovnik is a town with atractive beaches $\quad .632$

$\begin{array}{ll}\text { The coast of dubrovnik has many beautiful islands } & .6327\end{array}$

Dubrovnik has attractive natural attractions and scenary $\quad .644$

The quality of public transport is good $\quad .693$

$\begin{array}{ll}\text { The quality of taxi service is good } & .726\end{array}$

$\begin{array}{ll}\text { Local infrastructure is good } & .772 \\ \text { Commetianfastucture is good } & .711\end{array}$

Commertial infrastructure is good $\quad .711$

Dubrovnik has many quality restaurants $\quad .617$

Dubrovnik has many quality bars and discoteques $\quad .784$

Dubrovnik offers good sport and recreational activities $\quad .770$

Dubrovnik is a town with good nigthlife and entertainment $\quad .832$

Dubrovnik offers good shopping possibilities $\quad .637$

Dubrovnik is a town rich on cultural heritage $\quad .784$

Dubrovnik is a town of historical monuments, galleries and museums $\quad .859$

Dubrovnik is a town with good festivals, concerts and folclore $\quad .579$

Dubrovnik is a town of hospitality $\quad .778$

Residents of Dubrovnik are frendly $\quad .803$

Quality of life in Dubrovnik is good $\quad .629$

Residents of Dubrovnik speak foreign languages well $\quad .629$

Dubrovnik offers good value for money $\quad .547$

The atmosphere in Dubrovnik is relaxing $\quad .617$

The atmosphere in Dubrovnik is amusing/fun $\quad .533$

$\begin{array}{ll}\text { Dubrovnik is a safe destination to visit } & .5332\end{array}$

Visiting Dubrovnik is a pleasant experience $\quad .755$

Source: Results of the research

Results of exploratory factor analysis extracted 6 factors showing that measurement scales have necessary characteristics of convergent (related statements have high loadings on associated factors) and discriminant validity (related statements have low loading on other factors). Statements that are not loading significally on any factor are excluded from further research (fourteen statements).

Table 3: RMSEA Index and CMIN/DF indicator

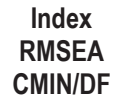

Source: Results of the research

Confirmatory factor analysis shows that RMSEA index is 0,063 which is significantly below the level of 0.08 , taken as a limit that model is adjusted with the data (Hair, Black, Babin and Anderson, 2010). CMIN/DF indicator of the quality of

\section{The value of the Index \\ 0,063 \\ 3,827}


model is 3.827 showing satisfactory level.

Table 4: Results of comparation between AVE and squared correlation between latent variables

\begin{tabular}{|c|c|c|c|c|c|c|}
\hline & Natural resources & Infrastructure & Leisure and recreation & Culture & Social environment & Atmosphere \\
\hline Natural resources & 0.305 & & & & & \\
\hline Infrastructure & 0.070756 & 0.314 & & & & \\
\hline Leisure and recreation & 0.080089 & 0.130321 & 0.381 & & & \\
\hline Culture & 0.257049 & 0.072361 & 0.045369 & 0.497 & & \\
\hline Social environment & 0.075625 & 0.2304 & 0.020449 & 0.157609 & 0.500 & \\
\hline Atmosphere & 0.287296 & 0.203401 & 0.106929 & 0.251001 & 0.070756 & 0.353 \\
\hline
\end{tabular}

Source: Results of the research

Results of comparation between AVE and squared correlation between latent variables show that absolute values of the correlation coefficients do not exceed limiting value of 0.85 , are in a range from 0.02 to 0.28 and are smaller than AVE ( 0.305 for natural resources and natural environment, 0.314 for infrastructure, 0.381 for leisure and recreation, 0.497 for culture, 0.5 for economic factors and social environment and 0.353 for the atmosphere of the place) confirming that analysed measurement scales have characteristic of discriminant validity.

The results of SEM testing (Scheme 1) show that (1) elements of natural resources and natural environment $(\beta=0.180 ; p=0.003)$, elements of tourist leisure and recreation $(\beta=0.305 ; p=0.000)$, economic factors and social environment $(\beta=0.186 ; p=0.001)$ and atmosphere of the place $(\beta=0.205 ; p=0.004)$ have positive influence on destination image. So, for the perception of image of Dubrovnik very important elements are: climate, cleanliness of the sea, coastline; quality of the restaurants, availability of sport and entertainment facilities, nightlife and shopping; good value for money, quality life of local people together with hospitality and friendliness of the local people and safe, interesting and relaxing atmosphere.

Elements of general and touristic infrastructure do not have statistically significant influence on destination image $(\beta=-0.093 ; p=0.051)$ as well as elements of culture, history and art $(\beta=0.062 ; p=0.215)$. The above mentioned can be explained by the fact that today more or less all tourism destinations have similar general and touristic infrastructure. So, infrastructure is one of the basic elements for tourism destination development and not the element of differentiation among destinations. Therefore it does not influence the image of a tourism destination. On the other hand results show that elements of culture, history and art do not influence image of Dubrovnik. The cause can be found in a fact that tourists visit Dubrovnik mainly for its outstanding cultural, historical and art accomplishment. Due to the fact that they have great expectation ex ante, by coming to Dubrovnik these expectations are fulfilled but not exceeded so they don't have influence on the image of Dubrovnik.

(2) destination image has positive influence on tourism satisfaction $(\beta=0.678, p=0.000)$.

Scheme 1: Structural model based on empirical results

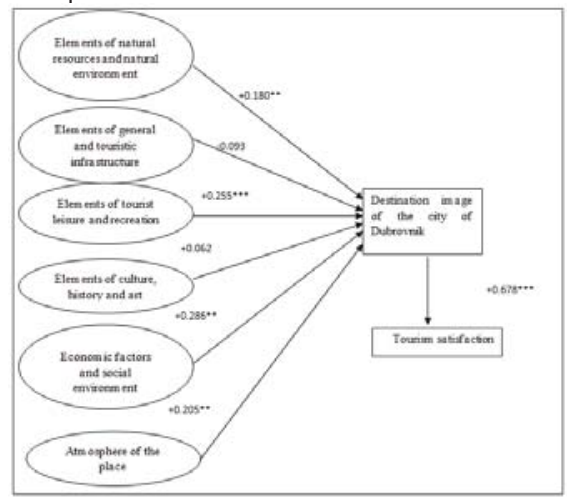

${ }^{*} \mathrm{p}$-values ${ }^{* *}<.01 ; * * *<.001$

Source: Author 


\section{Conclusion}

On a turbulent tourism market, with a growing number of international tourists on one side and destinations on the other side, competition is greater than ever. In order to stay competitive destinations are forced to find new ways of attracting tourists. In such conditions, image of destination is becoming more and more important and understanding the dimensions that influence image is becoming crucial for the destination marketing.

The aim of this paper was to define dimensions/factors that influence destination image as well as to explore relation between destination image and tourism satisfaction. The research was carried out in Dubrovnik, Croatia. The SEM results indicated that elements of natural resources and natural environment, tourist leisure and recreation, as well as economic factor and social environment and atmosphere of the place have positive influence on destination image. Also, the results indicate that destination image positively influences tourism satisfaction. These results will greatly benefit to the destination marketing of Dubrovnik as guidance for improving destination image of the city. Future studies should take into consideration the limitations of conducted research (convenience sampling, time of conducting - high seasonmeasurement of tourism satisfaction on one item scale) and include other concept $s$ that can influence tourism satisfaction (perceived quality, tourism motivation).

\section{References}

Ahmed, Z.U.: The influence of the components of a state's tourist image on product positioning strategy, Tourism Management, V.12, No.4, 1991, pp. 331-340

Baker, D. A. and Crompton J. L.: Quality, satisfaction and behaviour intentions, Annals of Tourism Research, V.27, N0.3, 2000, pp.785804

Baloglu, S. and McCleary, K. W.: A model of destination image formation, Annals of Tourism Research, V.26, No.4, 1999a, pp.868-897

Baloglu, S. and McCleary, K.W.: U.S. international pleasure travellers' images of four Mediterranean destinations: a comparation of visitors and nonvisitors, Journal of Travel Research. V.38, no.2, 1999b, pp.144-152

Baloglu, S., and Brinberg, D.: Affective images of tourism destinations, Journal of Travel Research, V. 35, No.4, 1997, pp.11-15

Beerli, A. and Martin, J.D.: Factors influencing destination image, Annals of Tourism Research, V.31, No.3, 2004, pp.657-681

Bigne Alcaniz, E. et al.: Relationship among residents' image, evaluation of the stay and post purchase behaviour, Journal of Vacation Marketing, V.11, No.4, 2005. pp.291-302

Bigne Alcaniz, E. et al.: The functional-psychological continuum in the cognitive image of a destination: A confirmatory analysis, Tourism management, 2008 - Article in press.

Bigne, J. E. et al., : Tourism image, evaluation variables and after purchase behaviour : inter-relationship, Tourism management, V.22, No. 6, 2001, pp. 607-616

Cai, L.A., Wu, B.T. and Bai, B.: Destination image and loyalty, Tourism Review International, V.7, No.3-4, 2003, pp.153-162

Castro, C., et al.: The influence of market heterogeneity on the relationship between a destination's image and tourists future behaviour, Tourism Management, V. 28, No. 1, 2007, pp.175-187

Chen, C. F. and Tsai, D.: How destination image and evaluative factors affect behavioural intentions? Tourism Management, V. 28, No.4, 2007, pp.1115-1122

Chi, C.G. and Qu, H.: Examining the structural relationship of destination image, tourist satisfaction and destination loyalty: An integrated approach, Tourism management, V.29, no.4, 2008. pp.624-636

Chon, K.: Understanding recreational travellers motivation, attitude and satisfaction, The Tourist Review, V.44, No.1, 1989, pp.3-7

Chon, K.S.: The role of destination image in tourism: a review and discussion, The Tourist Review, V.45, No.2, 1990, pp.2-9

Chung - Hsien et al.: Examining the role of cognitive and affective image in predicting choice across natural developed and theme park destinations, Journal of Travel Research, V.46, No.2, 2007, pp.183-194

Crompton, J. L.: An assessment of the image of Mexico as a vacation destination and the influence of geographical location upon that image, Journal of Travel Research, V.17, No.4, 1979, pp.18-23

Echtner, C.M. and Brent Ritchie, J.R.: The measurement of destination image: an empirical assessment; Journal of Travel Research, V.31, No.4, 1993, pp.3-13

Fakeye, P.C. and Crompton, J.L. : Image differences between prospective, first time, and repeat visitors to the lower Rio Grande valley, Journal of Travel Research, V.30, No.2, 1991, pp.10-16

Faullant, R., et al..: The impact of satisfaction and image on loyalty: the case of Alpine ski resorts, Managing Service quality, V.18, No.2, 2008, pp.163-178

Galarza, M. et al.: Destination image: towards a conceptual framework, Annals of Tourism Research, V.29. No.1, 2002, pp.56-78

Galarza, M. et al.: Destination image: towards a conceptual framework, Annals of Tourism Research, V.29. No.1, 2002, pp.56-78

Gartner, W.C. and Shen, J.: The impact of Tiananmen square on China's tourism image, Journal of Travel Research, V.30, No.4, 1992, pp.47-52

Giese, J.L. and Cote, and J.A.: Defining customer satisfaction, Academy of Marketing Science Review, No.1, 2000, www.amsreview.org/articles/giese01-2000.pdf, accessed 05.05.2012. 
Hair, J. F., Black, W. C., Babin, B. J. and Anderson, R. E.: Multivariate Data Analysis. A Global Perspective, 7th edition, Upper Saddle River: Pearson, 2010.

Hernandez - Lobato, L. et al.: Tourism destination image, satisfaction and loyalty: A study in Ixtapa-Zihuatanejo, Mexico, Tourism geographies, V. 8, No. 4, 2006, pp.343-358

Hosany, S. et al.: Destination Image and Destination Personality, International Journal of Culture, Tourism and Hospitality Research, V. 1 No.1, 2007, pp. 62-81

Hunt, J.D.: Image as a factor in tourism development, Journal of Travel Research, V.13, 1975, pp.1-7

Kozak, M. and Rimmington, M.: Tourist satisfaction with Mallorca, Spain, as an off-season holiday destination, Journal of Travel Research, V.38, No.3, 2000, pp.260-269

Lee, T.H.: A structural model to examine how destination image, attitude and motivation affect the future behaviour of tourists, Leisure Sciences, V.31, No.3, 2009, pp.215-236

Leisen, B.: Image segmentation: the case of a tourism destination, Journal of Services Marketing, V.15, No. 1, 2001, pp. 49-66

Martin Armario, E.: Tourist satisfaction: An analysis of its antecedents, http://dialnet.unirioja.es/, accessed 05.01.2012.

O' Leary S. and Deegan J.: Ireland's image as a tourism destination in France: attribute importance and performance, Journal of Travel Research, V. 43, No. 3, 2005, pp. 247-256

Okumus, A. and Yasin, B.: Examining the image of Italy, France and Marocco as a tourist destination, The 4th World conference for Graduate Research in Tourism, Hospitality and Leisure, April 2008, Turkey.

Pike, S. and Ryan, C.: Destination positioning trough a comparation of cognitive, affective and conative perceptions, Journal of Travel Research, V.42, No.4, 2004, pp. 333-342

Pike, S.: Destination image analysis- a review of 142 papers from 1973 to 2000., Tourism Management, V. 23, No. 5, 2002, pp. 541-549

Pike, S.: Literatura o imidžu destinacije od 2001. - 2007., Acta Turistica, V.19, No. 2, 2007, pp. 107-125

Prayag, G. and Ryan C.: Antecedents of tourists loyalty to Mauritius: The role and influence of destination image, place attachment, personal involvement and satisfaction, http:/lacademia.edu/, 2011, accessed 05.01.2012.

Prayag, G.: Tourists evaluations of destination image, satisfaction and future behavioural intentions - The case of Mauritius, Journal of Travel and Tourism marketing, V.26, No.8, 2009, pp. 836-853

Prebežac, D. and Mikulić, J.: Imidž destinacije i ključni čimbenici percipirane atraktivnosti destinacije, Tržište, V. 20, No. 2, 2008, pp. 163-178

Schneider, I. and Sonmez, S.: Exploring the touristic image of Jordan, Tourism Management, V. 20, No.4, 1999, pp. 539-542

Tasci, A.D.A. and Gartner, W.C.: Destination image and its functional relationship, Journal of Travel Research, V. 45, No.4, 2007, pp. 413-425

Troung, T.H. and King, B.: An evaluation of satisfaction levels among Chinese tourists in Vietnam, International Journal of Tourism Research, V.11, No.6, 2009, pp. 521-535

Truong, T. and Foster, D.: Using HOLSAT to evaluate tourist satisfaction at destinations: The case of Australian holidaymakers in Vietnam, Tourism Management, V.27, No.5, 2006, pp. 842-855

Wang, C. and Hsu, M.K.: The relationship of destination image, satisfaction and behaviour intentions: an integrated model, Journal of Travel and Tourism marketing, V.27, No.8, 2010, pp.829-843

Xia, W. et al. Examining antecedents and consequences of tourist satisfaction: A structural modelling approach, Tsingua Science and Technology, V.14, No.3, 2009, pp.397-406 